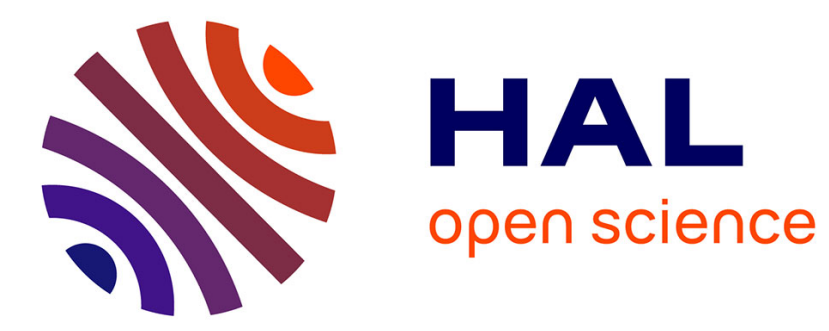

\title{
Optical study of using ceramic foams for volumetric solar receivers
}

Mahmoud Mahmoud Alaa Ali, Mohamed Rady, Mohamed Attia, Emad Ewais

\section{To cite this version:}

Mahmoud Mahmoud Alaa Ali, Mohamed Rady, Mohamed Attia, Emad Ewais. Optical study of using ceramic foams for volumetric solar receivers. IEEEXplore Digital Library, 2017, pp.284-289. 10.1109/IRSEC.2016.7983917 . hal-02145237

\section{HAL Id: hal-02145237 \\ https://hal.science/hal-02145237}

Submitted on 5 Apr 2020

HAL is a multi-disciplinary open access archive for the deposit and dissemination of scientific research documents, whether they are published or not. The documents may come from teaching and research institutions in France or abroad, or from public or private research centers.
L'archive ouverte pluridisciplinaire HAL, est destinée au dépôt et à la diffusion de documents scientifiques de niveau recherche, publiés ou non, émanant des établissements d'enseignement et de recherche français ou étrangers, des laboratoires publics ou privés. 


\section{Optical Study of using Ceramic Foams for Volumetric Solar Receivers}

\author{
Mahmoud Alaa, Mohamed Rady*, Mohamed Attia \\ Faculty of Engineering at Helwan \\ Helwan University \\ Cairo, Egypt \\ mahmoud alaa3110@yahoo.com; makrady@yahoo.com;
} e mabdalla@hotmail.com

\author{
Emad Ewais \\ Refractory and Ceramic Materials Division \\ Central Metallurgical R\&D Institute (CMRDI) \\ Cairo, Egypt \\ dr_ewais@hotmail.com
}

\begin{abstract}
Ceramic foams are promising materials for volumetric solar receivers in concentrated solar power (CSP) plants. Understanding the solar heat flux distribution on the receiver is of great importance for optimizing the receiver volumetric efficiency and thermal performance. This work presents a 3D optical analysis of ceramic based volumetric solar receivers. The optical analysis is conducted using a Monte Carlo based solar ray tracing software. Ceramic foams are represented by idealized packed tetrakaidecahedron structures. The absorbed heat flux distribution and the effect of cell size, porosity and absorptivity on the penetration depth of the absorbed heat flux are investigated. Comparisons have been made with extruded honeycomb receivers. The results clearly demonstrate the dependence of flux distribution and penetration depth of solar rays on the material absorptivity and structure. The simulation results show a uniform heat flux distribution on the frontal faces with an intensity that increases with increasing the material absorptivity. Both the porosity and the cell size have a great effect on the penetration depth of the absorbed heat flux. In general, foam structure shows larger penetration depths than extruded honeycombs.
\end{abstract}

Keywords-component; Volumetric solar receiver; Solar furnace; Solar radiation; Optical simulation; Monte Carlo ; Solar ray tracing; Optical efficiency

\section{INTRODUCTION}

Concentrating Solar Power (CSP) is considered to be one of the most promising and sustainable technologies for electricity production in the future. Many types of CSP technologies have been identified such as linear Fresnel, dish design, parabolic trough and solar tower. Solar Tower Power Plants (STPP) are based on the concept of focusing solar radiation using a heliostat field on a receiver at the top of a tower, which absorbs the solar radiation and converts it to a high temperature heat. In past decades both tubular and volumetric receivers have been used, but the volumetric receiver is more efficient than tubular receivers due to their three dimensional configuration. In case of volumetric receivers, a Heat Transfer Fluid (HTF), usually air, passes through the receiver and removes the heat by forced convection. This heat is then used for electricity production.

Different designs of volumetric receivers have been investigated experimentally and numerically. They differ by the material and the structure of the receiver. Both metallic as well as ceramic materials have been used. Different structures include wire mesh, extruded honeycombs with parallel channels and open cell foam [1].

In order to design and optimize the volumetric solar receiver and increase its efficiency, complex and highly coupled numerical simulations are essential. These simulations involve optical, heat transfer, fluid flow, and thermal stress analysis. Optical analysis is implemented to calculate the absorbed heat flux distribution which represents a radiative heat source in the energy equation of the CFD model. The absorbed solar heat flux distribution has a great effect on the temperature distribution of the solid and fluid phases and the resulting thermal stresses.

A lot of theoretical research work has been done on honeycomb structure to predict the absorbed solar heat flux distribution. Generally two approaches have been used to describe the absorbed solar heat flux distribution for the honeycomb structure: the Monte Carlo Ray Tracing (MCRT) method [2-3], or Beer Lambert law based on Extinction coefficient [4-5]. MCRT method is an effective method in case of complex geometries. Beer Lambert law has many disadvantages such as neglecting the direction effects of the incoming light.

Regarding foam structure, different models have been used in order to compute the radiative term, such as the two flux approximation [6-7], the Rosseland diffusion equation [8-9] and the P-1 model [10]. However, in the previous studies, the real geometry of the foam structure is not considered and simple representation of the structure as a porous media is employed. Dealing with the solar radiation propagation as standalone physic has not been comprehensively studied. Furthermore, for heat transfer analysis of foam based volumetric solar receivers, many researchers represented the distribution of the absorbed solar radiation using a simplified heat flux boundary condition.

In the present work, a comprehensive 3D optical simulation of volumetric solar receivers employing ceramic foams has been carried out using a MCRT based software. The flux distribution on the receiver surface has been obtained and analyzed. This flux distribution shall be used in future detailed thermal analysis. The effect of optical properties and structure parameters of ceramic foams have been studied to understand the effect of these parameters on 
the absorbed flux distribution. Comparisons have been also made with extruded honeycomb receivers.

\section{OPTICAL SIMULATION}

The optical simulation is conducted using a Monte Carlo (MC) based solar ray tracing software Tonatiuh: an objectoriented program written in $\mathrm{C}++$, which has been experimentally validated [11-12]. Tonatiuh includes three basic models: a model for the incident solar radiation, a model for the concentration system, and a model for the basic interaction between radiation and elements of concentration system [13]. The model representing the concentration system consists of a set of surfaces both real and virtual which are used to define locations at which radiation data are required, an input aperture, and a volume. The interactions between the radiation and the concentration system are modeled using MC methods [14-15]. Ray tracing is used to track the paths of the photons through the concentration system until they exit the volume or completely absorbed.

The Monte Carlo algorithm implemented in Tonatiuh allows tracing and collecting the scattering and absorption of each photon simulated. By fixing a certain position of the sun in the sky, thus a value of solar power, and the total number of photons, Tonatiuh directly assigns to each of them a discrete value of energy, power per photon (PPP) calculated according to Eq.1.

$$
P P P=\frac{\text { solar power }}{\text { totalnumber of photons }}\left[\frac{\text { Watt }}{\text { Photon }}\right]
$$

The accuracy and resolution of results increases with the increase of the number of photons implemented in the simulation. Actually, the physical model for optical analysis for STPP consists of a heliostat field focusing the solar radiation on the receiver positioned at the top of a central tower. In laboratory testing, solar furnace facilities are used to analyze the performance of solar receivers. It consists of the sun, reflector, concentrator, and the receiver. The present analysis has implemented an optical model based on the solar furnace geometry as shown in Fig. (1).

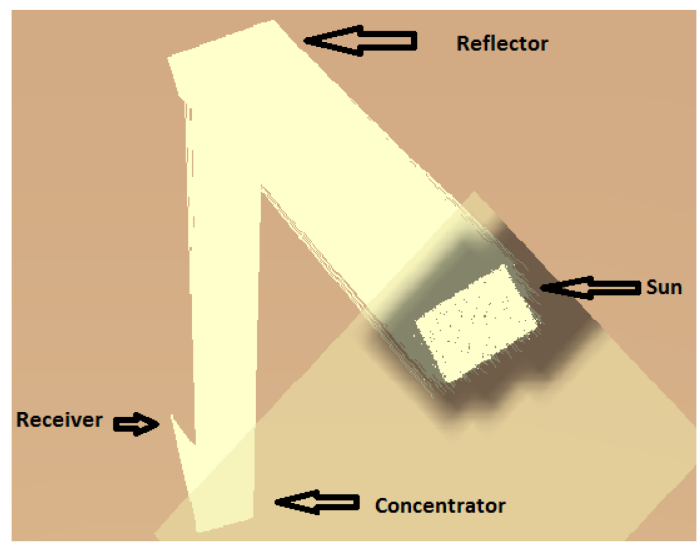

Figure 1. Solar furnace optical model.

\section{A. Solar Receiver Geometry}

In the present work, two different receiver structures have been studied: honeycomb structure and foam structure. The honeycomb structure is the same as the one used in SolAir3000, it has a honeycomb like structure, composed of several cups, and each cup is formed by equal parallel channels as shown in Fig. (2) [16]. The foam structure is represented by idealized packed tetrakaidecahedron cell as shown in Fig. (3). the cross section area of the receiver is about $15 \times 15 \mathrm{~mm}$ and the axial depth is $50 \mathrm{~mm}$.
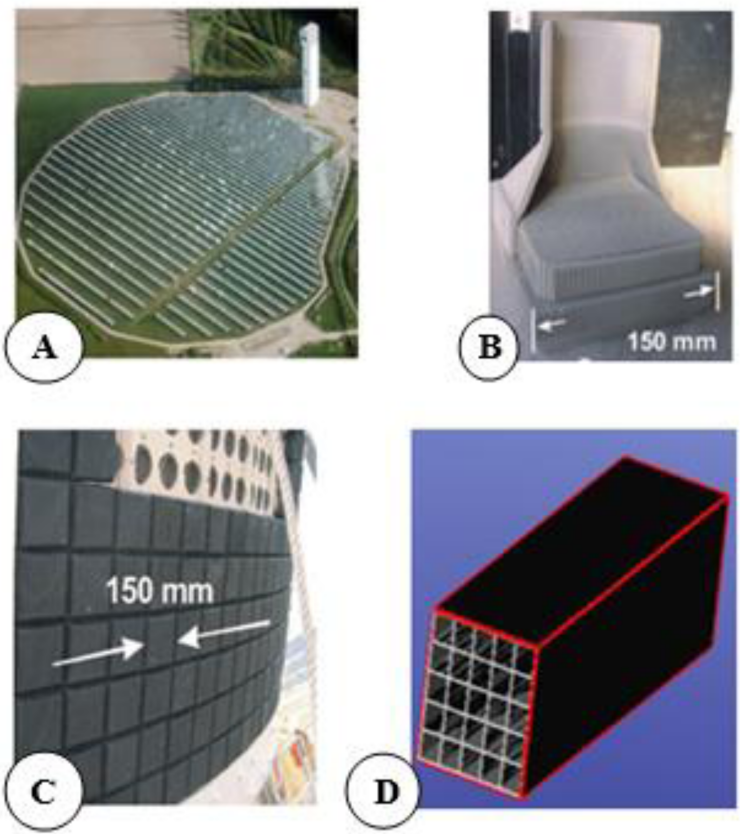

Figure 2. (A) Jülich solar tower. (B) a part of single absorber module. (C) receiver during installation. (D) honeycomb geometry used for current simulation

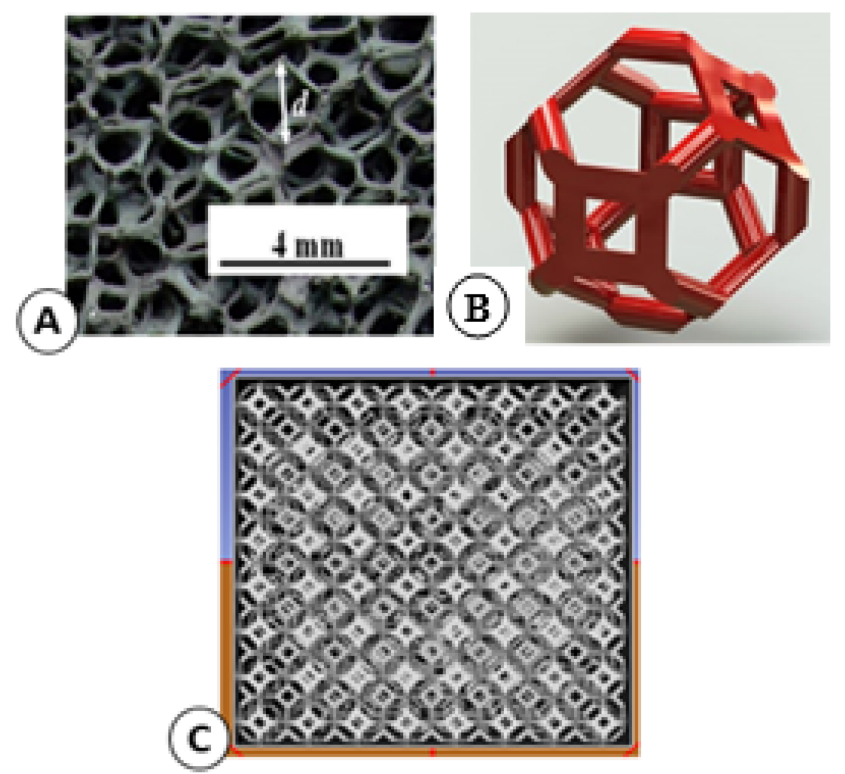

Figure 3. (A) Foam sample. (B) unit tetrakaidecahedron cell. (C) foam absorber created for current simulation. 


\section{B. Receiver Material}

Since in high temperature solar applications values above $800{ }^{\circ} \mathrm{C}$ are reached, ceramic materials are the most suitable option for this application due to their high melting point compared to metallic materials. In this study three ceramic materials have been investigated. These include infiltrated silicon carbide ( $\mathrm{SiC}$ ), infiltrated silicon carbide with selective coating ( $\mathrm{SiC}$ with selective coating), and alumina $\left(\mathrm{Al}_{2} \mathrm{O}_{3}\right)$. Both $\mathrm{SiC}$ and $\mathrm{SiC}$ with selective coating are widely used in volumetric solar receivers [17]. The solar absorptivity of $\mathrm{SiC}$ and $\mathrm{SiC}$ coated is 0.8 and 0.95 , respectively. In the present study, Alumina has been introduced for volumetric solar receivers as low cost candidate. Alumina is a well-balanced material with great thermal, mechanical and chemical properties, featuring high mechanical strength, high wear resistance, and thermal stability. However, the solar absorptivity of $\mathrm{Al}_{2} \mathrm{O}_{3}$ is low (about 0.2). Optical analysis of $\mathrm{Al}_{2} \mathrm{O}_{3}$ shall help in understanding the effect of its low absorptivity on the distribution of the absorbed solar heat flux in comparison with conventional used materials and studying enhancement methods.

\section{Sun Definition and Solar Heat Flux Calculation}

The sun shape has been modeled as Pillbox shape. The number of solar rays used is $10^{7}$ ray. The direct normal incident radiation is considered as $1000 \mathrm{KW} / \mathrm{m}^{2}$. As mentioned before the receiver size is smaller than the solar image reflected by the heliostat and the concentrator, so it can be fairly assumed that the frontal face has a constant flux distribution and calculated according to Eq.2.

$$
q_{\text {Frontal Face }}=\frac{N_{\text {ph.abs }} * P P P}{\text { area }}
$$

Where, $\mathrm{N}_{\text {ph.abs }}$ is the number of absorbed photons on the frontal face area. Equation (2) has been applied for all channels simulated then the mean value of the heat flux has been calculated using a "Matlab" developed program.

\section{RESULTS AND DISCUSSION}

\section{A. Honeycomb Structure}

Figure (4) shows the convention used to name the frontal and internal faces of a honeycomb channel. The incident solar rays hit the upper face with an incident solar ray angle $\beta$ then reflect to the other faces. Figure (5) shows the flux distribution along the upper face of the absorber as function of the axial depth $Z$. The flux peak is located at the entrance of the upper face as the solar rays directly reflected from the concentrator. Also the upper face receives the largest number of solar rays. The photons reflected from the upper face are absorbed by the lower face, so the flux peak is located on deeper sections as shown in Fig. (6). Due to symmetry, the heat flux for both right and left face is equal as depicted in Fig (7). The results show that the flux distributions on each face of an extruded honeycomb channel are not similar. The absorbed solar heat flux by the upper face decreases and the reflected number of photons to the lower face increases with the decrease of material absorptivity. Also, the absorbed solar radiation by the frontal face decreases with decreasing absorptivity.

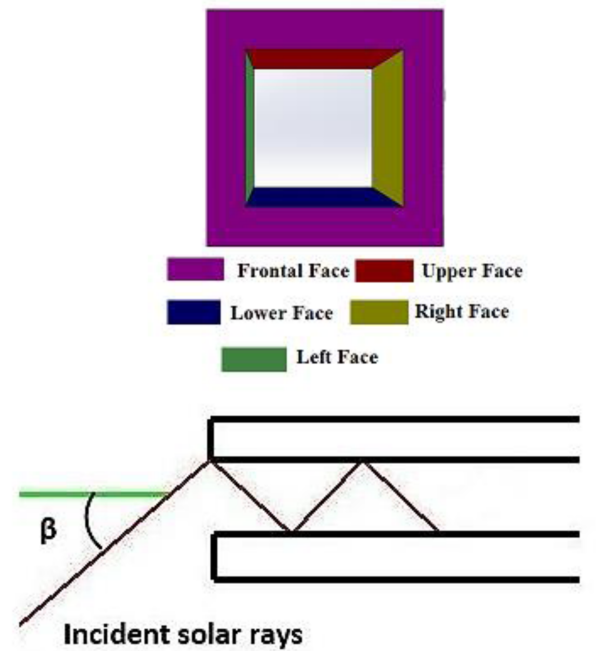

Figure 4. (a) Convention used to name the extruded honeycomb faces, (b) incidence angle of solar rays.

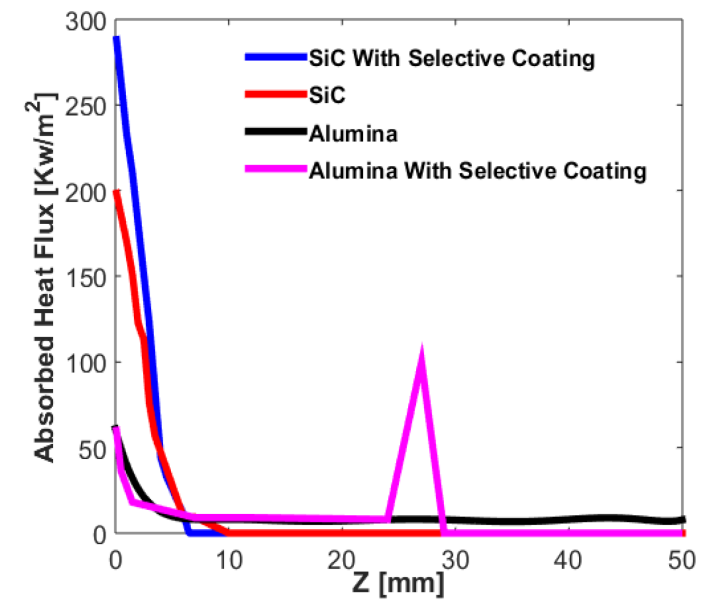

Figure 5. Absorbed solar heat flux distribution on the upper face for extruded honeycomb structure.

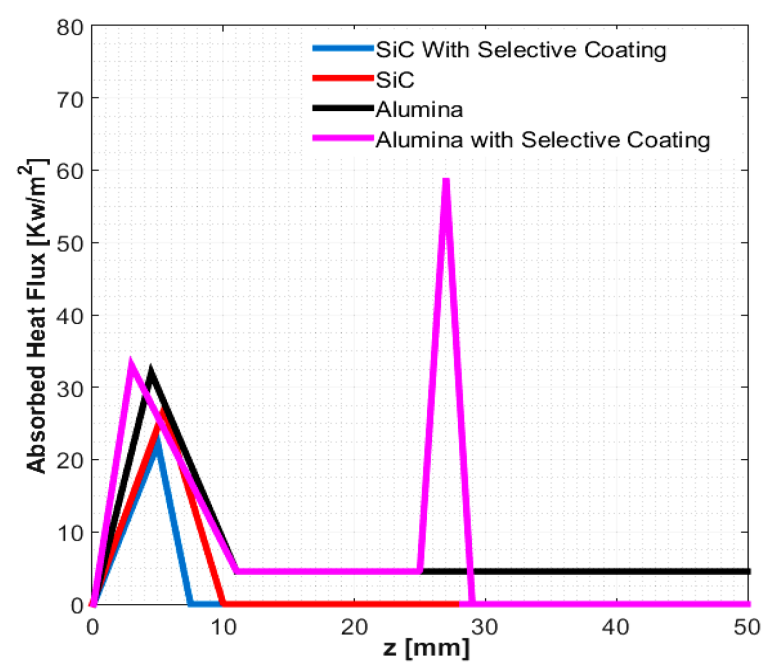

Figure 6. Absorbed solar heat flux distribution on the lower face for extruded honeycomb structure. 


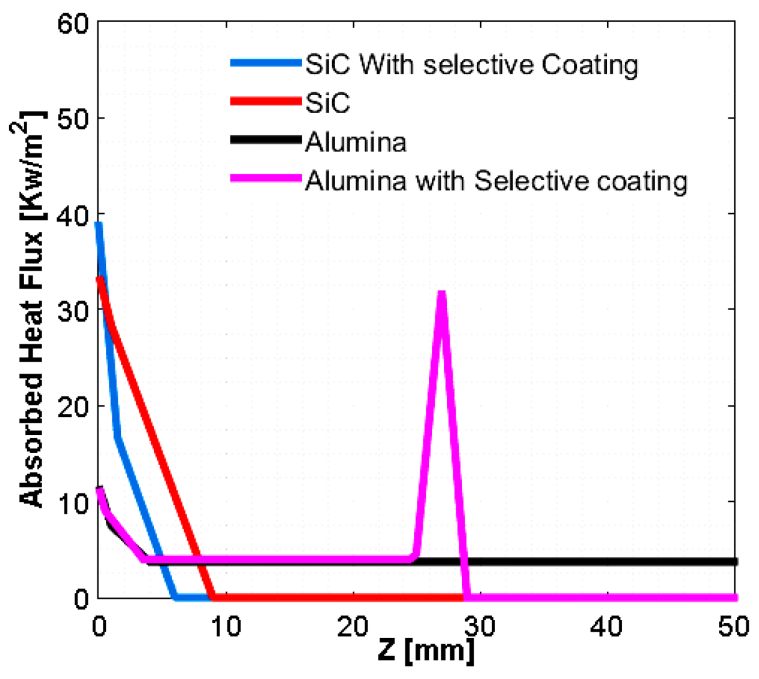

Figure 7. Absorbed solar heat flux distribution on right face for extruded honeycomb structure.

In case of material with low absorptivity $\left(\mathrm{Al}_{2} \mathrm{O}_{3}\right)$ the photons run away from the back of the receiver and the flux intensity on the frontal face is very small compared to SiC, which resulted in low optical efficiency. To solve this issue, it's proposed to apply selective coating of 0.95 absorptivity on the frontal face and the last $25 \mathrm{~mm}$ depth from the back surface. As can be seen from the results the heat flux on the frontal face increases to reach the same value of $\mathrm{SiC}$ with selective coating, see Fig. (8). Also a maximum peak of the absorbed solar heat flux exists in all faces after $25 \mathrm{~mm}$ from the entrance of the channel. Using this technique leads to increase the penetration depth, the optical efficiency, and prevent photons from escaping from the back of the receiver.

As mentioned in the introduction, in case of honeycomb structure Beer Lambert Law (BLL) is widely used to describe the absorbed solar heat flux according to Eq.3 [4, $5]$.

$$
I=I_{0} \cdot e^{-\xi \cdot Z}
$$

Where $\mathrm{I}\left(\mathrm{W} / \mathrm{m}^{2}\right)$ is the absorbed solar heat flux, $\mathrm{I}_{0}$ $\left(\mathrm{W} / \mathrm{m}^{2}\right)$ is the incident heat flux, $\xi(1 / \mathrm{m})$ is the extinction coefficient taken from [16], and $Z$ is the axial Depth (m). In case of $\mathrm{SiC}$ honeycomb, Fig. (9) shows a comparison of the absorbed solar heat flux distribution predicted by current simulation and by BLL. According to Eq. 3 at $Z=0, I=I_{0}$. BLL neglects the reflection loses linked to the radiation that was not absorbed by the receiver but, instead, reflected to the outside. Furthermore BLL does not take into account the spillage of the heliostat. As a result, the total absorbed heat flux obtained by using BLL is larger than that obtained by the current simulation. Using BLL to compute the radiative heat source of the energy equation leads to overestimating the mean temperature distribution of the solid phase and fluid phase as reported in [18].

\section{B. Foam Structure}

Figure (10) shows the absorbed solar heat flux of $\mathrm{SiC}$ with selective coating as a function of the axial depth $\mathrm{Z}$ for different values of cell size (Dp). The foam structure parameters significantly affect the distribution of the absorbed heat flux distribution.

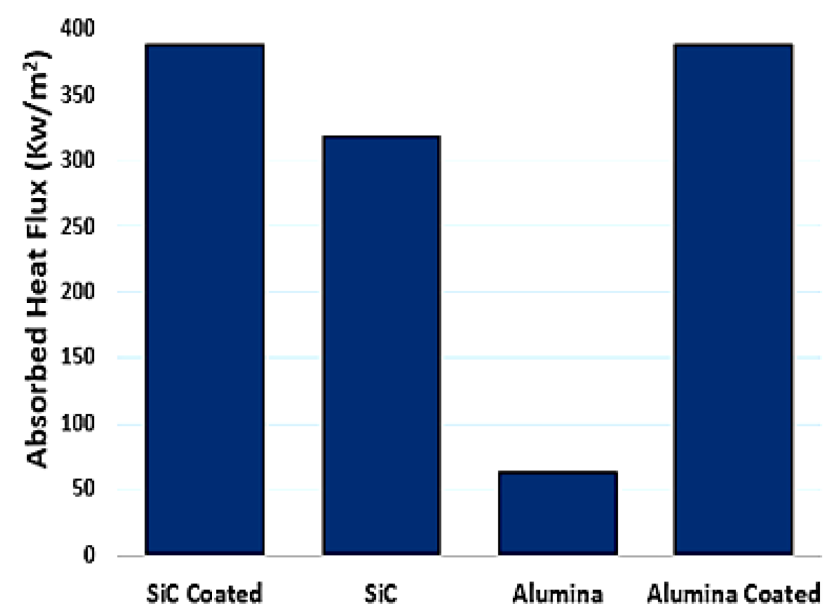

Figure 8. Absorbed solar heat flux on frontal face for extruded honevcomb structure.

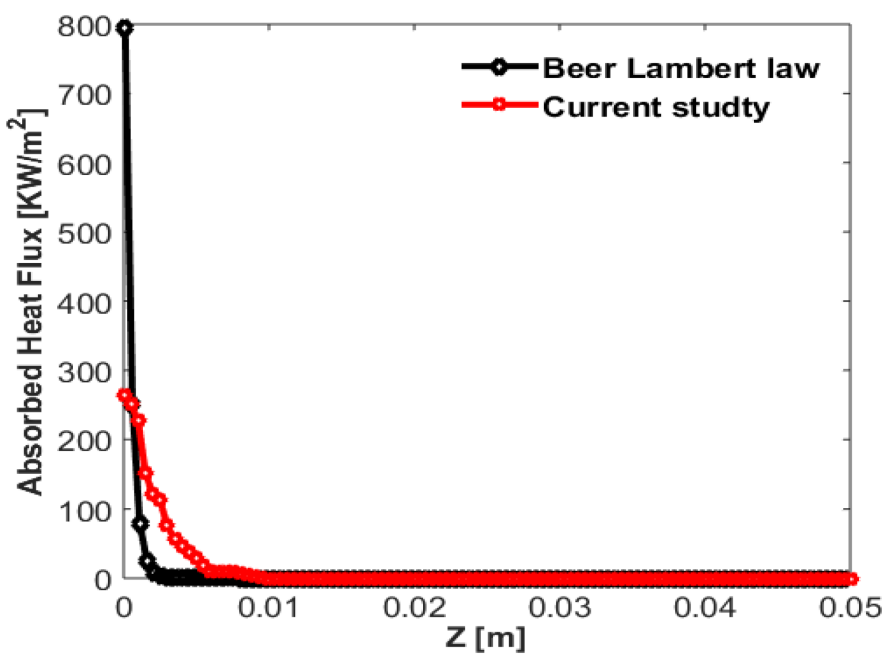

Figure 9. Comparison of solar flux distribution for $\mathrm{SiC}$ honeycomb structure predicted by current simulation and Beer Lambert law.

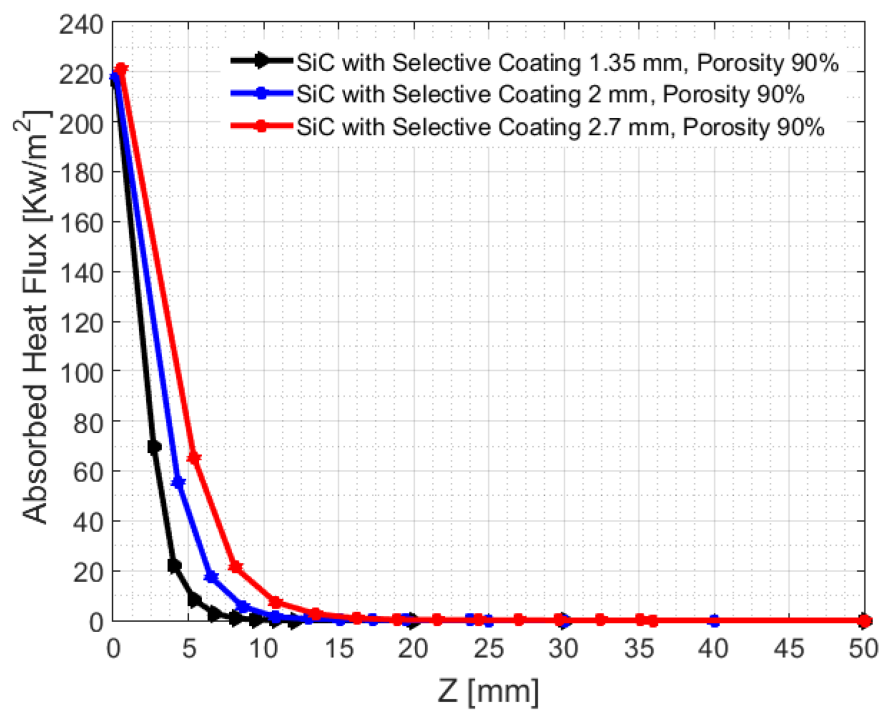

Figure 10. Absorbed solar heat flux distribution of $\mathrm{SiC}$ foam with selective coating for different values of cell size. 
The absorbed solar heat flux decreases rapidly along the axial coordinate. The penetration depth increases with increasing the mean cell size or the porosity (Po) (Fig.11). This can be attributed to that the decrease of the extinction coefficient of porous media with increasing porosity or mean cell size. In case of $\mathrm{SiC}$ with selective coating, the curve have been fitted to exponential law to obtain the extinction coefficient $(\mathrm{Dp}=2.7 \mathrm{~mm}, \mathrm{Po}=0.9, \xi=0.2375 \mathrm{~mm}-1)$ with relative RMS error of $3.945 \%$. The value of $\xi$ obtained is in a good agreement with the results in [19]. Also, decreasing the absorptivity leads to increase the penetration depth. The similar trend can be observed for all materials investigated. In case of alumina foam, the incident photons never run away from the back of the receiver Compared to honeycomb structure as shown in fig. (12)

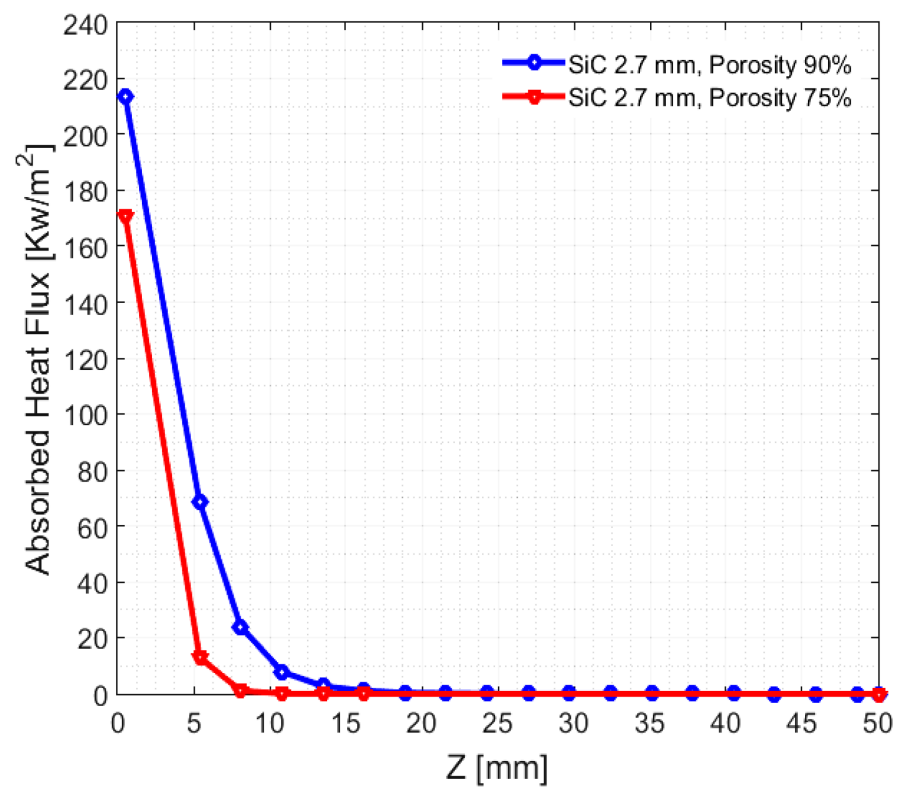

Figure 11. Effect of foam porosity on the penetration depth of the absorbed solar heat flux.

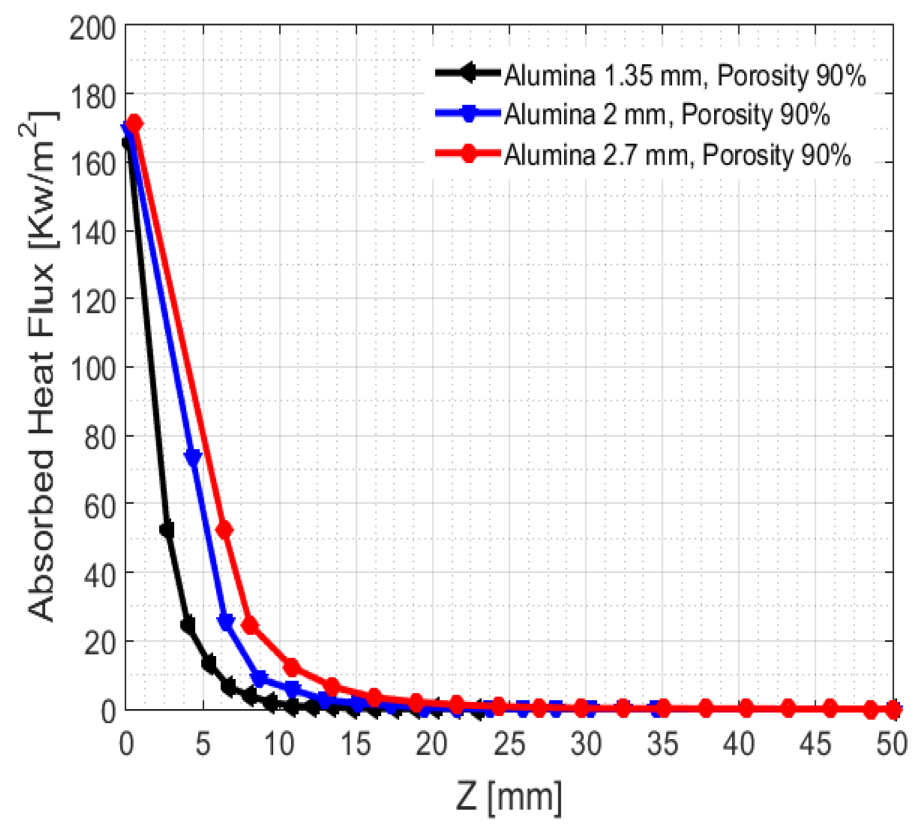

Figure 12. Absobed solar heat flux distribution for Alumina foam.

\section{Optical Efficiency}

The optical efficiency has been calculated according to Eq.4.

$$
\boldsymbol{\eta}=\mathbf{P}_{\text {abs }} / \mathbf{P}_{\text {in }}
$$

Where $\mathrm{P}_{\mathrm{abs}}$ is the absorbed photons by the receiver and $\mathrm{P}_{\text {in }}$ is the total number of photons impinging on the receiver. The optical efficiency has been calculated for foam structures and honeycomb structures. All results are summarized in Table 1. As can been seen from the results, the optical efficiency of foam structure is higher than the honeycomb structure. The difference is significant using Alumina. Thus indicating that foam structure is more convenient for low absorptivity materials. Further enhancement of optical efficiency can be achieved using selective coating.

Table 1: Optical efficiency of different volumetric receivers' structures

\begin{tabular}{|c|c|c|c|c|}
\hline Material & Structure & Porosity & $\begin{array}{c}\text { Cell Size } \\
(\mathrm{mm})\end{array}$ & $\begin{array}{c}\text { Optical } \\
\text { Efficiency } \%\end{array}$ \\
\hline $\begin{array}{l}\text { SiC with } \\
\text { selective } \\
\text { coating }\end{array}$ & \multirow{4}{*}{ Honeycomb } & \multirow{4}{*}{0.495} & 2 & 94.7 \\
\hline $\mathrm{SiC}$ & & & 2 & 83.23 \\
\hline $\mathrm{Al}_{2} \mathrm{O}_{3}$ & & & 2 & 20.17 \\
\hline $\begin{array}{c}\mathrm{Al}_{2} \mathrm{O}_{3} \\
\text { with } \\
\text { selective } \\
\text { coating }\end{array}$ & & & 2 & 87.56 \\
\hline \multirow{4}{*}{$\begin{array}{l}\text { SiC with } \\
\text { selective } \\
\text { coating }\end{array}$} & \multirow{4}{*}{ Foam } & 0.9 & 1.35 & 95.17 \\
\hline & & 0.9 & 2 & 95.13 \\
\hline & & 0.75 & 2 & 92.12 \\
\hline & & 0.75 & 2.7 & 92.09 \\
\hline \multirow{4}{*}{$\mathrm{SiC}$} & \multirow{4}{*}{ Foam } & 0.9 & 1.35 & 93.21 \\
\hline & & 0.9 & 2 & 93.16 \\
\hline & & 0.75 & 2 & 91.75 \\
\hline & & 0.75 & 2.7 & 91.64 \\
\hline \multirow{4}{*}{$\mathrm{Al}_{2} \mathrm{O}_{3}$} & \multirow{4}{*}{ Foam } & 0.9 & 1.35 & 78.14 \\
\hline & & 0.9 & 2 & 76.27 \\
\hline & & 0.75 & 2 & 73.11 \\
\hline & & 0.75 & 2.7 & 71.24 \\
\hline
\end{tabular}

IV. CONCLUSION

In this study, a 3D optical simulation has been carried out in order to understand the effect of structure parameters and the material absorptivity on the absorbed solar heat flux in volumetric solar receivers. The following conclusions have been drawn.

- The heat flux distribution of honeycomb structures is highly non-uniform with prominent peaks and surface dependent. For foam structures, the heat flux decreases rapidly with the receiver depth. In general, volumetric solar receivers with foam structure has higher optical efficiency than honeycomb structure.

- The foam porous structure parameters significantly affect the distribution of the absorbed solar heat flux. The penetration depth increases with the increase of porosity and mean cell size. 
- The solar absorptivity of the material significantly affects the penetration depth of the absorbed solar heat flux. The effect is more significant for honeycomb solar receivers and the photons can run away from the back of the receiver for low values of absorptivity.

- Alumina has been introduced as a low cost candidate for volumetric solar receivers with favorable mechanical and thermal properties. For reducing the effects of low absorptivity of Alumina, a simple technique for applying selective coating on the frontal face and the last $25 \mathrm{~mm}$ depth from the back surface of Alumina honeycomb structure leads to increasing the heat flux penetration depth and optical efficiency. However, the results indicate that foam structure is more convenient for using Alumina with values of optical efficiency approaching high cost $\mathrm{SiC}$ ceramics. Further enhancement of the optical efficiency can be achieved using selective coating techniques.

\section{ACKNOWLEDGMENT}

These investigations are supported by the European Union Seventh Framework Program (FP7) under grant agreement no. 608593 (eurosunmed).

\section{REFERENCES}

[1] A. Ávilla-marín, "Volumetric receivers in Solar Thermal Power Plants with Central Receiver System technology: A review," Solar Energy, vol. 85, pp. 891-910, 2011.

[2] F. Gomez-Garcia, J. Gonzalez-Aguilar, S. Tamayo-Pacheco, G. Olalde and M. Romero, "Numerical analysis of radiation propagation in a multi-layer volumetric solar absorber composed of a stack of square grids," Solar Energy, vol. 121, pp. 94-102, 2015.

[3] H.-J. Lee, J.-K. Kim, S.-N. Lee and Y.-H. Kang, "Consistent heat transfer analysis for performance evaluation of multichannel solar absorbers," Solar Energy, vol. 86, pp. 1576-1585, 2012.

[4] P. Schwarzbözl, U. Hack and M. Ebert, "Improvement of ceramic absorbers materials for open volumetric receivers," in Proceedings of the 17th SolarPACES Conference, Granada, Spain, 2011.

[5] M. Roldan, O. Smirnova, T. Fend, J. Casas and E. Zarza, "Thermal analysis and design of a volumetric solar absorber depending on the porosity," Renewable Energy, vol. 62, pp. 116-128, 2014.

[6] A. Kribus, M. Grijnevich, Y. Gray and C. Caliot, "Parametric study of volumetric absorber performance," Energy procedia, vol. 49, pp. 408-417, 2014.

[7] S. Mey, C. Caliot, G. Flamant, A. Kribus and Y. Gray, "Optimization of High Temperature SiC Volumetric Solar Absorber," Energy Procedia, vol. 49, pp. 478-487, 2014

[8] F. Wang, Y. Shuai, H. Tan and C. Yu, "Thermal performance analysis of porous media receiver with concentrated solar irradiation," International Journal of Heat and Mass Transfer, vol. 62, pp. 247-254, 2013.

[9] Y. Sano, S. Iwase and A. Nakayama, "A Local Thermal Nonequilibrium Analysis of Silicon Carbide Ceramic Foam as a Solar Volumetric Receiver," Journal of Solar Energy Engineering, vol. 134, p. $021006,2012$.

[10] Z. Wu, C. Caliot, G. Flamant and Z. Wang, "Coupled radiation and flow modeling in ceramic foam volumetric solar air receivers," Solar Energy, vol. 85, pp. 2374-2385, 2011.
[11] M. Blanco, A. Mutuberria, D. Martinez and R. Albert, "Results of the Empirical Validation of Tonatiuh at Mini-Pegase CNRS-PROMES Facility," in in Proceedings of the 17th SolarPACES Conference, Granada, Spain, 2011.

[12] M. Blanco, A. Mutuberria and Martinez, "Experimental Validation of Tonatiuh Using the Plataforma Solar de Almería Secondary Concentrator Test Campaign Data," in in Proceedings of the 16th SolarPACES Conference, Perpignan, France, 2010.

[13] M. Blanco, M. Amieva and A. Mancillas, "The Tonatiuh Software Development Project: An Open Source Approach to the Simulation of Solar Concentrating Systems," in Proceedings of IMECE, Orlando, Florida, USA, 2005.

[14] G. Fishman, Monte Carlo Concepts, Algorithms, and Applications, Springer-verlag, 1996.

[15] J. Gentle, Random number generation and Monte Carlo methods, Springer-velag, 2003.

[16] T. Fend, P. Schwarzbözl, O. Smirnova, D. Schöllgen and C. Jakob, "Numerical investigation of flow and heat transfer in a volumetric solar receiver," Renewable energy, vol. 60, pp. 655-661, 2013.

[17] F. Gomez-Garcia, J. González-Aguilar, G. Olalde and M. Romero, "Thermal and hydrodynamic behavior of ceramic volumetric absorbers for central receiver solar power plants: A review," Renewable and Sustainable Energy Reviews, vol. 57, pp. 648-658, 2016.

[18] R. Capuano, T. Fend, P. Schwarzbözl, O. Smirnova, H. Stadler, B. Hoffschmidt and R. Pitz-Paal, "Numerical models of advanced ceramic absorbers for volumetric solar receivers," Renewable and Sustainable Energy Reviews, vol. 58, pp. 656-665, 2016.

[19] J. Petrasch, P. Wyss and A. Steinfeld, "Tomography-based Monte Carlo determination of radiative properties of reticulate porous ceramics," Journal of Quantitative Spectroscopy \& Radiative Transfer, vol. 105, pp. 180-197, 2007. 